\title{
Site Diversity Gain for Earth-to-Satellite Links Using Rain Intensity Measurement
}

\author{
Md Rafiqul Islam*, Ali Kadhim Lwas, M. H. Habaebi \\ Electrical and Computer Engineering Department, Faculty of Engineering \\ International Islamic University Malaysia \\ Jalan Gombak, 53100 Kuala Lumpur, Malaysia \\ e-mail: rafiq@iium.edu.my*, alilawas@yahoo.com
}

\begin{abstract}
Site diversity technique is effective method to overcome rain attenuation, mostly in the tropics where high precipitation is predominant. The method is analyzed based on measurements in two locations separated by $37.36 \mathrm{Km}$ in Malaysia. From concurrent measured rain intensities of two locations at IIUM and UKM for one year, it was found that only ten concurrent events had occurred containing highest rain intensities of $18 \mathrm{~mm} / \mathrm{h}$ with outage probability of $0.00154 \%$ on two locations out of about 381 events experienced over one year period. These findings will be very useful for Earth-to-satellite link designers to improve reliability by applying site diversity as a rain fade mitigation technique at any frequency.
\end{abstract}

Keywords: Site diversity technique, Rain intensity, Site diversity gain, Perdiction models

\section{Introduction}

Microwave links that use frequency higher than $10 \mathrm{GHz}$ have a serious problem with weather, primarily rain. The rain causes attenuation to communication signal through the rain fall, which is directly proportional to the frequency [1]. It may be too severe for a long time causing service disruptions. This problem can be overcome directly by providing appropriate power margins for the system in two directions uplink and downlink. This technique can achieve its results by either increasing the antenna size or raising the radio transmission power. The two methods may be used together to encounter the problem. Limitations on the communication satellite transmission power and base station radiated power, imposed by international agreements, and are assumed to be the main obstacle to increasing the radio transmission power. Most likely, these limitations will affect high frequencies in the $\mathrm{Ku}, \mathrm{Ka}$ and $\mathrm{V}$ bands, if the attenuation exceeds the available power margin. Hence, the need to develop alternative techniques to deal with the acute attenuation conditions and improves the performance of the link. Different methods are available to overcome propagation effects. Frequency bands, system objective and network geometry are the parameters that should be taken into account to choose a suitable technique to mitigate the propagation effects. [2-6].

Diversity is one of the best techniques used in satellite communications to counteract the effects of link fading $[7,8]$. The diversity can be defined as the repetition or redundancy of information. When using diversity techniques, the receiver makes the diversity decisions while the transmitter is unaware of them [9]. The efficiency of diversity techniques stem from the fact that fade of the branches is considered independent or their envelopes are uncorrelated. There are five widely used techniques of diversity in practice today, namely; site, frequency, time, orbital and polarization $[9,10]$.

Site diversity is the use of two or more connected receivers to reduce or evade rain effects on downlink throughout periods of heavy rainfall on one path of the earth to satellite paths. Site diversity enhances the satellite communications reliability. Furthermore, site diversity improves overall satellite link performance by exploiting the limited extent and size of the intense cell [11]. This technique exploits the physical fact that the rain structure is not uniform spatially and that most likely the intense rain cells cover a limited area. The comparison between received signals of two or more sites and selecting the signal has least attenuation is achieved by the operating center [12)]. In addition, the switched signal has less attenuation among the received signals where the probability of heavy rainfall occurs at the same time on all sites is very low, this probability decreases with the distance between sites increases [10],[13]. 
The models used to predict the site diversity performance are divided into empirical prediction and physical-mathematical models [14]. The high cost and complex interconnectivity are assumed the downside to this technique.

There are a number of variable factors involved while applying this technique, namely; site separation, frequency, elevation angle, baseline orientation angle, polarization angle, and wind direction. The impact of site diversity technique on the performance of system can be determined by finding the statistical rain attenuation for a reference signal and diversity joints. The diversity gain, $G_{S D}(P)$, is the difference between the attenuation values at \% time [15].

$$
G_{S D}(P)=A_{s}(P)-A_{j}(P)
$$

where $A_{s}$ and $A_{j}$ are the single site and joint attenuation values at the probability in percentage respectively. Figure 1 depicts the diversity gain prediction.

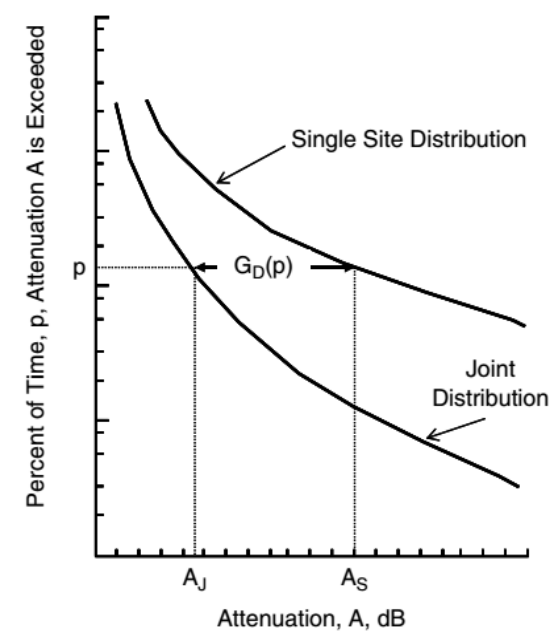

Figure 1. Definition of diversity gain

Two tipping bucket rain gauges with $0.2 \mathrm{~mm}$ and $0.1 \mathrm{~mm}$ resolutions were also installed in IIUM and UKM respectively. For these two locations separated by $37.36 \mathrm{~km}$, the rain rate were measured synchronously for one year period to analyse site diversity mitigation.

\section{Prediction Models}

This section will discuss previous models done on site diversity techniques. Some climates studied in these works differ from Malaysian climate but within the frequency band of interest that is Ku-band and above. In addition, there are other research works that were carried out at different frequency bands, and were done in tropical climate.

\subsection{Hodge Model}

The study proposes an empirical model to estimate diversity gain for satellite links. The proposed model is a function of the distance separating earth terminals, signal frequency, elevation angle, and angle between the baseline and the path azimuth. The authors of this study base their analysis on the results of 34 diversity experiments, which have been conducted in Canada, England, Japan, and the United States over a period of 10 years. The model is expressed by the following equation [16].

$$
G(D, f, \theta, \beta)=G_{D} G_{f} G_{\theta} G_{\beta}
$$

where 


$$
\begin{aligned}
& G_{D}=a\left(1-e^{-b D}\right) \\
& a=0.64 A-1.6\left(1-e^{-0.11 A}\right) \\
& b=0.585\left(1-e^{-0.098 A}\right) \\
& G_{f}=1.64 e^{-0.025 f} \\
& G_{\theta}=0.004970+0.834 \\
& G_{\beta}=-0.00177 \beta+0.887
\end{aligned}
$$

where $A$ is the rain attenuation $(\mathrm{dB})$ of a single site, $D$ is the site separation $(\mathrm{km}), f$ is the operating frequency $(\mathrm{GHz}), \theta$ is the elevation angle (degrees) of the link path and $\beta$ is the orientation of baseline in-relation to the transmission path.

\subsection{ITU-R Model}

The diversity gain ( $\mathrm{dB}$ ) according to ITU-R [17] is represented as a product of the gains contributed by spatial separation $G_{d}$, frequency $G_{f}$, elevation angle $G_{\theta}$ and baseline dependent term $G_{\beta}$

$$
G_{S D}=G_{D} G_{f} G_{\theta} G_{\beta}
$$

where

$$
\begin{aligned}
& G_{D}=a\left(1-e^{-b D}\right) \\
& a=0.78 A-1.94\left(1-e^{-0.11 A}\right) \\
& b=0.59\left(1-e^{-0.1 A}\right) \\
& G_{f}=1.64 e^{-0.025 f} \\
& G_{\theta}=1+0.006 \theta \\
& G_{\beta}=1+0.002 \beta
\end{aligned}
$$

The distance separating the two sites, $d$ is in kilometers; $A$ is the path rain attenuation in decibels, $f$ is the frequency in gigahertz, $\theta$ is the elevation angle of the link path in degrees, and $\beta$ is the angle made by the azimuth of the propagation path with respect to the baseline between the sites, chosen such that $\beta \leq 90^{\circ}$.

\subsection{Panagopoulos Model}

According to [18] simple formulas are proposed to estimate the gain as a result of the use of site diversity method. The diversity gain model underwent wide testing. It is validated for site diversity system separated by distance is below $15 \mathrm{~km}$. The model can be expressed by the following equation

$$
G_{S D}=G_{A_{S}} G_{D} G_{f} G_{\theta} G_{\beta}
$$

where $A_{S}$ (decibels) presents the attenuation of the single site. Each factor is calculated according to

$$
\begin{aligned}
& A_{S}=8.19 A_{S}^{0.0004}+0.1809 A_{S}-8.2612 \\
& G_{D}=\ln (3.610 D) \\
& G_{f}=\exp (-0.0006 f) \\
& \left.G_{\theta}=1.23471-\theta^{-0.356}\right) \\
& G_{\beta}=1-0.0000 \emptyset
\end{aligned}
$$




\subsection{Nagaraja and Otung Model}

The study [19] develops an empirical model for the statistical prediction of dual site diversity gain, using rain data collected from the Nimrod weather system over 46 months. The study's main contribution lies in incorporating exceedance time percentage and extremely high frequency bands in the range of $16 \mathrm{GHz}$ to $50 \mathrm{GHz}$. The model is a function of several parameters, including time percentage of average year, the distance between sites $(\mathrm{km})$, the orientation of the baseline (degrees), the frequency $(\mathrm{GHz})$ and the elevation angle (degrees). The prediction model is expressed in the following equation

$$
G_{S D}=G_{(p, D, \beta)} G_{f} G_{\theta}
$$

where $G_{f}$ refers to the site diversity gain as a function of the link frequency, while the $G_{\theta}$ refers to the site diversity gain as function of elevation angle and $G_{(p, D, \beta)}$ is a function of the time percentage of average year, site separation and baseline orientation. The final model can be expressed by

$$
\begin{aligned}
G_{(p, D, \beta, f, \theta)}= & \left(2.92 \times 10^{-2}+5.67 \times 10^{-4} D\right) f^{1.19} \exp [(b / p)-0.546 \ln (p) \\
& \left.+d p \ln (p)-2.55 \sin \theta+1.45 \sin ^{2} \theta\right]
\end{aligned}
$$

where $b$ and $d$ are parameters that depend on values of site separation and baseline orientation [19].

\subsection{Semire Model}

In [20][23], authors developed a prediction model using rain attenuation measurements and TRMM radar data collected in five Southeast Asian countries. The study introduces two improvements on an existing model, namely; the inclusion of low elevation angles and a high link frequency up to $70 \mathrm{GHz}$. The new model's performance was validated using three existing site diversity models while varying link parameters. Based on this validation, the authors show that the proposed model can be used to predict site diversity gains in relation to site separation and elevations angle with better accuracy, as compared to the three examined models. The

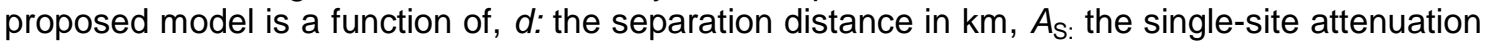
in $\mathrm{dB}, f$ : the link frequency in $\mathrm{GHz}, \theta$ : the angle of elevation in degrees and $\beta$ : the baseline orientation angle in degrees.

The process followed by the proposed prediction model is similar to that of the Hodge model; however it employs expressions and coefficients that are more applicable to tropical regions. The model is expressed by the following equation:

$$
G(d, f, \theta, \beta)=G_{d} G_{f} G_{\theta} G_{\beta}
$$

where

$$
\begin{aligned}
& G_{d}=a\left(1-e^{-b d}\right) \\
& \left.a=0.7755 A_{S}+0.33741+e^{-9.16 A_{s}}\right) \\
& \left.b=0.15841+e^{-0.031644_{s}}\right) \\
& G_{f}=1.006 e^{-0.0015 f}-0.395 e^{-0.473 f} \\
& G_{\theta}=0.899\left(1+\theta^{-0.683}\right) \\
& G_{\beta}=-0.000001 \not 8+0.9877
\end{aligned}
$$

\section{Data Collection}

Two locations, namely IIUM Gombak and UKM Bangi are proposed to analysis site diversity. The coordinates are $3.2528^{\circ} \mathrm{N}, 101.7372^{\circ} \mathrm{E}$ and $2.91972^{\circ} \mathrm{N} 101.78139^{\circ} \mathrm{E}$ for IIUM and UKM respectively. The distance between IIUM and UKM is determined according to formula of great-circle distance for two points. The great-circle distance is defined as the straight distance 
between 2 points based on their coordinates. The distance is equal to $37.36 \mathrm{~km}$. The rain intensity at IIUM and UKM are used for evaluation the site diversity technique. The rain rate at IIUM and UKM are measured from January 1, 2015 to December 31, 2015 concurrently using real-time rain gauges.

\section{Analysis of Rain Rate Data}

Out of 381 considerable raining events on both sites, only ten of these events were concurrently and they are depicted in Table 1.

\begin{tabular}{|c|c|c|}
\hline Event date & IIUM & UKM \\
\hline 13/2/2015 & $19: 28 \mathrm{pm}$ until 19:57 pm & $19: 46 \mathrm{pm}$ until 21:54 pm \\
\hline $21 / 3 / 2015$ & $17: 40 \mathrm{pm}$ until $18: 40 \mathrm{pm}$ & $17: 39 \mathrm{pm}$ until $17: 53 \mathrm{pm}$ \\
\hline 19/4/2015 & $18: 15 \mathrm{pm}$ until $19: 32 \mathrm{pm}$ & 19:01 pm until 19:06 pm \\
\hline $1 / 6 / 2015$ & $17: 24 \mathrm{pm}$ until $17: 52 \mathrm{pm}$ & $17: 43 \mathrm{pm}$ until $18: 38 \mathrm{pm}$ \\
\hline 2/6/2015 & $14: 04 \mathrm{pm}$ until 15:09 pm & $14: 53 \mathrm{pm}$ until $15: 35 \mathrm{pm}$ \\
\hline 4/8/2015 & 00:48 am until 01:28 am & 01:12 am until 01:47 am \\
\hline $5 / 11 / 2015$ & $14: 30 \mathrm{pm}$ until $15: 33 \mathrm{pm}$ & $14: 42 \mathrm{pm}$ until $14: 58 \mathrm{pm}$ \\
\hline $13 / 11 / 2015$ & $13: 37 \mathrm{pm}$ until $14: 52 \mathrm{pm}$ & $13: 40 \mathrm{pm}$ until $13: 57 \mathrm{pm}$ \\
\hline $15 / 11 / 2015$ & 13:11 pm until 13:18 pm & 13:11 pm until 13:17 pm \\
\hline $25 / 11 / 2015$ & 07:52 am until 9:11 am & 07:45 am until 08:11 am \\
\hline
\end{tabular}

The Table 1 points out the overlapping rain events over one year and their details such as date and time of occurrence for both sides at IIUM and UKM.

Figure 2 and 3 show these simultaneous rainfall events as a function of time in both locations. Figure 3 presents the first instantaneous event dated on February 13, 2015. From this figure, it is observed that the highest value of rainfall intensity during overlapping time at IIUM is $24 \mathrm{~mm} / \mathrm{h}$ which is double the observed reading at UKM $(12 \mathrm{~mm} / \mathrm{h})$. This result supports the idea of site diversity mitigation technique to overcome rain attenuation.

According to Figure 3 , the range of falling rain rate is from $0 \mathrm{~mm} / \mathrm{h}$ to $36 \mathrm{~mm} / \mathrm{h}$ at IIUM campus while it is minimum $0 \mathrm{~mm} / \mathrm{h}$ to maximum $12 \mathrm{~mm} / \mathrm{h}$ in the span of the whole event at UKM campus.

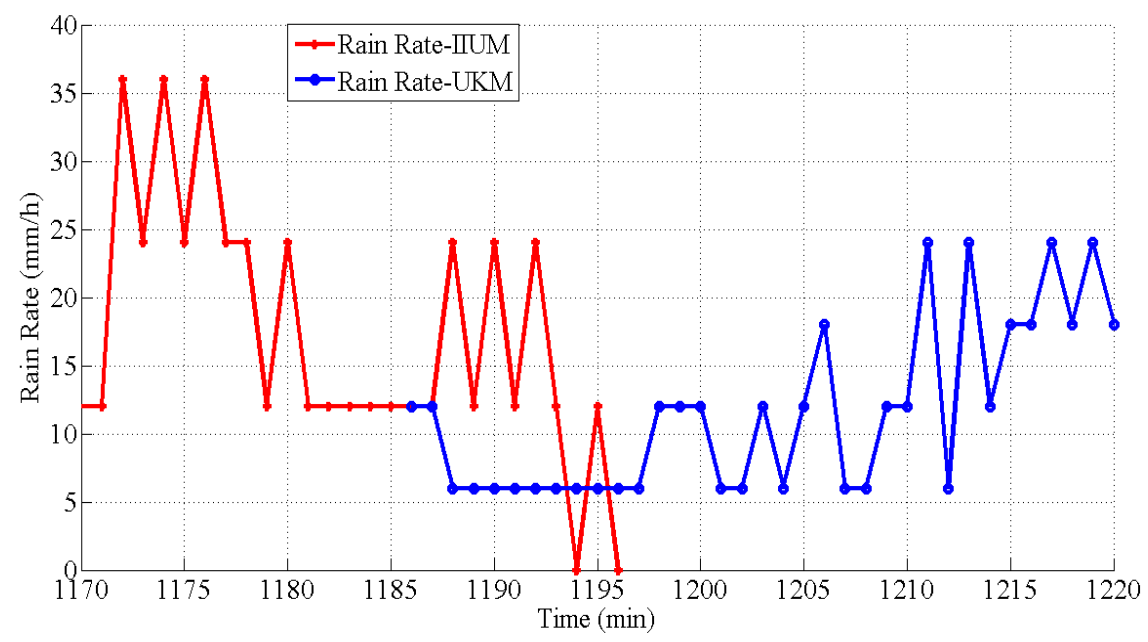

Figure 2. Concurrent event on February 13, 2015 for duration 8 minutes. 


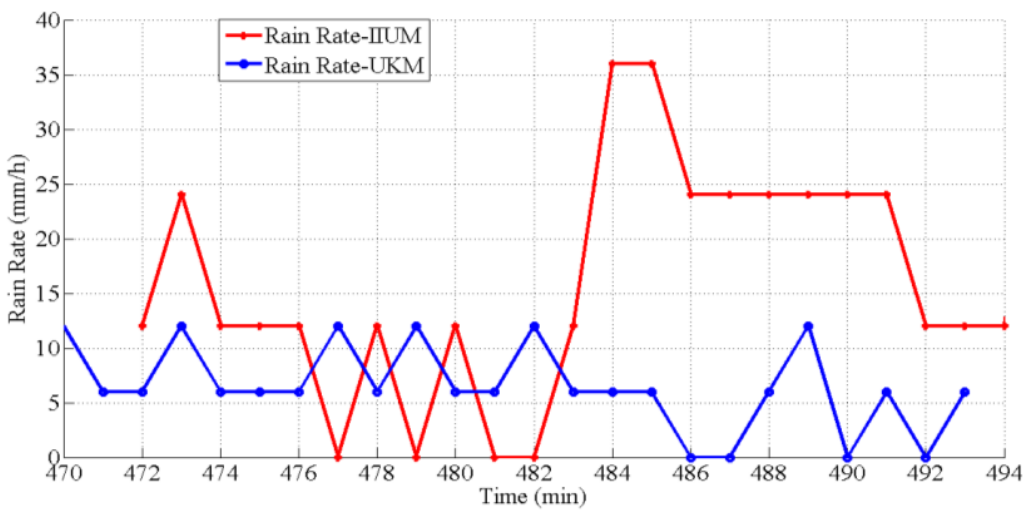

Figure 3. Concurrent event on November 25, 2015 for 14 minutes duration.

For all overlapping events, it can be observed that only ten concurrent events are found between IIUM and UKM out of 381 events measured in both sides. Although, the author in [21] reported that the rain cell size in tropical area is less than $15 \mathrm{~km}$, but measurement shows that it reached up to $37 \mathrm{Km}$. During ten simultaneous events lowest intensity is found $6 \mathrm{~mm} / \mathrm{h}$ in UKM site while $156 \mathrm{~mm} / \mathrm{hr}$ is observed in IIUM site. Lowest rain intensities are found 6, 12 and 18 $\mathrm{mm} / \mathrm{hr}$ during overlapping time. These rain intensities are considered as predominant impairments to weaken the satellite signal performance using site diversity between these two stations.

Period of simultaneously occurred ten rainfall events are presented in Table 2. For the one year data, concurrent time of 113 minutes is collected. Out of these overlapping time, rain intensity of $6 \mathrm{~mm} / \mathrm{h}$ is occurred for a period of 85 minutes, $12 \mathrm{~mm} / \mathrm{hr}$ for 26 minutes and 18 $\mathrm{mm} / \mathrm{h}$ for 2 minutes are recorded. Outage probabilities of theses rain intensities are calculated and presented in Table 2. Based on the value of outage probabilities, the link availability can be achieved around $99.99 \%$ by designing the link considering rain rate of $6 \mathrm{~mm} / \mathrm{hr}$ at $0.01 \%$. Preliminary results on the performance of site diversity indicate that diversity technique could be applied between two locations (IIUM and UKM campuses) to obtain the highest link availability. Separation distance which is larger than rain cell size reduces the probability of concurrent rain events at both locations, as a result, a high diversity gain as the separation distance increases.

Table 2. Duration and outage probability of simultaneously occurred rainfall

\begin{tabular}{llll}
\hline overlapping period & $6 \mathrm{~mm} / \mathrm{h}$ & $12 \mathrm{~mm} / \mathrm{h}$ & $18 \mathrm{~mm} / \mathrm{h}$ \\
\hline Figure 5.15 (8 minutes) & 6 & 2 & - \\
Figure 5.16 (14 minutes) & 11 & 2 & 1 \\
Figure 5.17 (6 minutes) & 3 & 2 & 1 \\
Figure 5.18 (10 minutes) & 8 & 2 & - \\
Figure 5.19 (17 minutes) & 10 & 7 & - \\
Figure 5.20 (10 minutes) & 10 & - & - \\
Figure 5.21 (13 minutes) & 9 & 4 & - \\
Figure 5.21 (14 minutes) & 11 & 3 & - \\
Figure 5.23 (7 minutes) & 5 & 2 & - \\
Figure 5.24 (14 minutes) & 12 & 2 & - \\
Total & 85 & 26 & 2 \\
Probability in percentage & 0.0162 & 0.00497 & 0.000381 \\
\hline
\end{tabular}

\section{Site Diversity Analysis and Discussion}

The cumulative distribution of measured rain rate at IIUM and that of jointly between IIUM and UKM are analysed based on diversity concept and shown in Figure 4. Joint distribution only includes three values 6,12 and $18 \mathrm{~mm} / \mathrm{h}$, which have probability of $0.0162 \%$, $0.00497 \%$ and $0.000381 \%$ respectively. Rain rate distribution measured at IIUM and that measured jointly at IIUM and UKM are converted to rain attenuation distribution using proposed model [22] as shown in Figure 5. This figure depicts comparison between rain attenuation at IIUM and diversity between IIUM and UKM. 


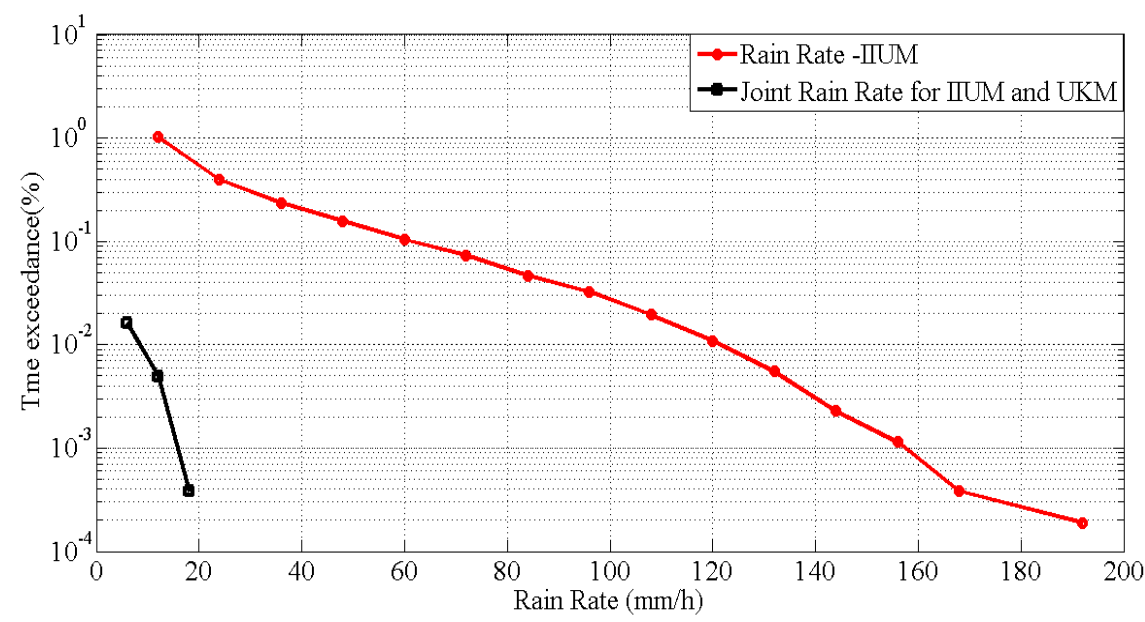

Figure 4. Cumulative Distribution Function of Rain Intensity of IIUM and Joint Distribution of IIUM and UKM Measured during 2015.

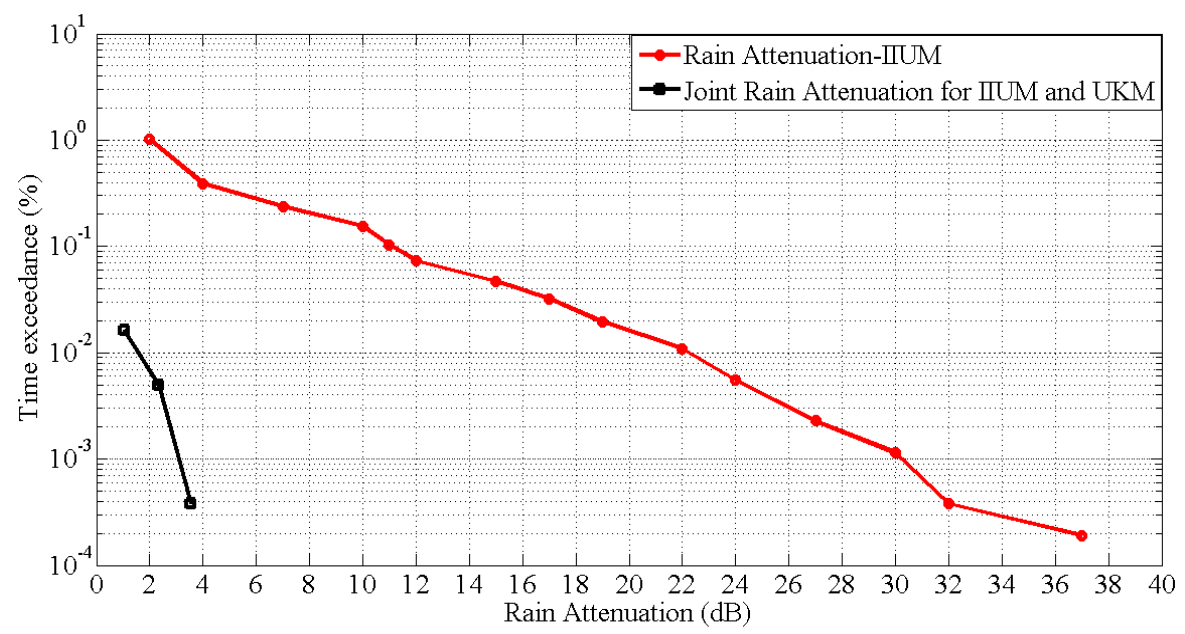

Figure Error! No text of specified style in document.5. Cumulative Distribution Function of converted rain attenuation of IIUM and Joint Distribution of IIUM and UKM using measured rain rate for 2015.

In order to analyse site diversity gain model, MEASAT3 (geostationary at $91.5^{\circ} \mathrm{E}$ ) is assumed as reference satellite and Kulliyyah of Engineering, International Islamic University Malaysia $\left(3.2528^{\circ} \mathrm{N}, 101.7372^{\circ} \mathrm{E}\right)$ is assumed as reference base station and Faculty of Engineering, UKM $\left(2.91972^{\circ} \mathrm{N} 101.78139^{\circ} \mathrm{E}\right)$ as diversity station. Table 3 shows the technical parameters of the system.

Table 3. Technical parameters of the outdoor system.

\begin{tabular}{ll}
\hline Ground Station Location & $3.2528^{\circ} \mathrm{N}, 101.7372^{\circ} \mathrm{E}$ \\
\hline Satellite Position & $91.5^{\circ} \mathrm{E}$ \\
Azimuth Angle & $253^{\circ}$ \\
Elevation Angle & $77.4^{\circ}$ \\
Polarization & Vertical \\
Frequency & $12 \mathrm{GHz}$ \\
\hline
\end{tabular}


Diversity gain are calculated based on Hodge (2), ITU-R (4), Panagopoulos (6) and Semire (10) prediction models using parameters given in Table 3 and those measured from Figure 4 and 5 and presented in Figure 6 and Figure 7 for baseline angles of $90^{\circ}$ and $0^{0}$ respectively. The result indicates that the measured site diversity gain is very close to that predicted by ITU-R and Hodge model for baseline angle of $90^{\circ}$ with $37.36 \mathrm{~km}$ separation and MEASAT3 as reference satellite. Predictions by Semire underestimates the measurement $8 \mathrm{~dB}$ and $6 \mathrm{~dB}$ at single site fade of $32 \mathrm{~dB}$ and $22 \mathrm{~dB}$ respectively; while Panagopoulos underestimates $5 \mathrm{~dB}$ and $3 \mathrm{~dB}$ for single site fade of 32 and $22 \mathrm{~dB}$ respectively. However, all models underestimate the measurement for baseline angle of $0^{0}$.

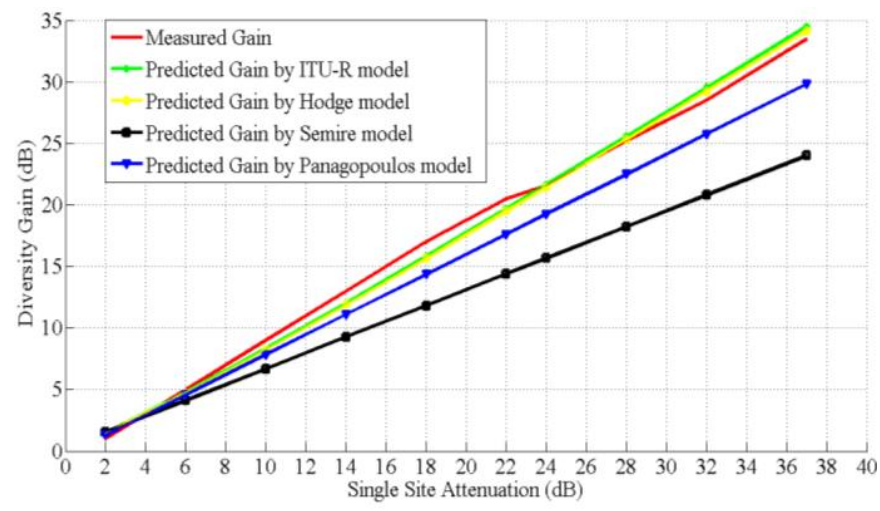

Figure 6. Comparison of site diversity gain prediction models with measured site diversity gain for base line orientation of 90 degree in Kuala Lumpur, Malaysia.

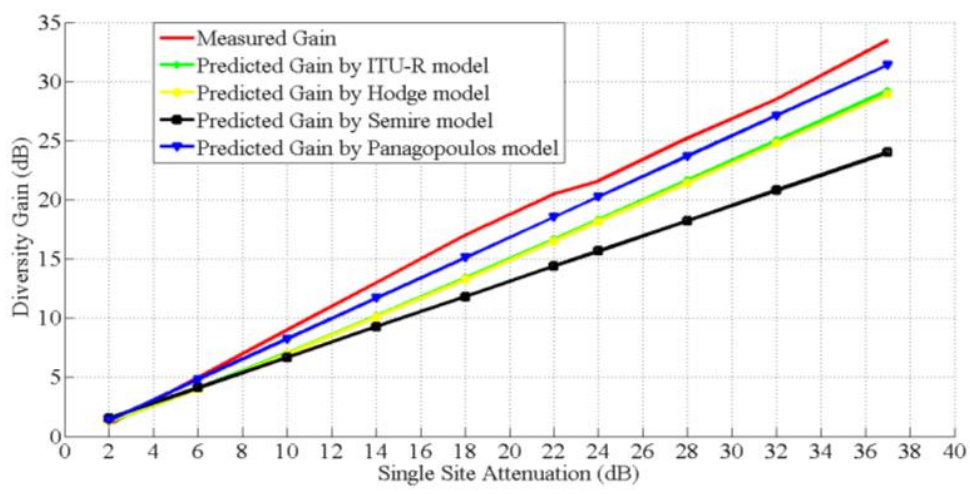

Figure Error! No text of specified style in document.7. Comparison of site diversity gain prediction models with measured site diversity gain for base line orientation of 0 degree in Kuala Lumpur, Malaysia.

\section{Conclusion}

Site diversity technique is analyzed based on 1-minute rain rate measurements in two locations separated by $37.36 \mathrm{Km}$ in Malaysia for one year period. From analysis, it is found that 10 raining events occurred concurrently in both sites out of 381 measured events in a year. By analyzing all overlapping raining events, joint probability distribution was calculated and found three values of 6,12 and $18 \mathrm{~mm} / \mathrm{h}$, are $0.0162 \%, 0.00497 \%$ and $0.000381 \%$ respectively. In order to investigate diversity gain, measured rain rate distribution is converted to rain attenuation distribution using proposed model and compare with those predicted by ITU-R, Hodge, Panagopoulos and Semire prediction models. The result indicates that the measured site diversity gain is very close to that predicted by ITU-R and Hodge model for baseline angle of 90 with $37.36 \mathrm{~km}$ separation and MEASAT3 as reference satellite. Predictions by Semire 
underestimates the measurement $8 \mathrm{~dB}$ and $6 \mathrm{~dB}$ at single site fade of $32 \mathrm{~dB}$ and $22 \mathrm{~dB}$ respectively; while Panagopoulos underestimates $5 \mathrm{~dB}$ and $3 \mathrm{~dB}$ for single site fade of 32 and $22 \mathrm{~dB}$ respectively. However, all models underestimate the measurement for baseline angle of $0^{0}$. These findings will be very useful for Earth-to-satellite link designers to improve reliability by applying site diversity as a rain fade mitigation technique at any frequency.

\section{References}

[1] Lwas AK, Islam MR, Habaebi MH, Mandeep SJ, Ismail AF, Zyoud A. Effects of wind velocity on slant path rain-attenuation for satellite application in Malaysia. Acta Astronautica. 2015; 117:402-407.

[2] Willis MJ, Evans BG. Fade countermeasures at Ka band for Olympus. International Journal of Satellite Communications and Networking. 1988; 1;6(3):301-11.

[3] Allnutt JE. Recent developments in propagation counter-measures for VSAT services. In Antennas and Propagation. Eighth International Conference on. 1993: 198-201.

[4] Acosta RJ. Rain fade compensation alternatives for Ka band communication satellites. National Aeronautics and Space Administration. 1997: 145-152.

[5] Majithiya P, Sisodia AK, Muralidhar V, Garg VK. Novel down link rain fade mitigation technique for Ka- band multibeam systems. International Journal of Satellite Communications and Networking. 2007; 25(1):45-51.

[6] Testoni A, Bousquet M, Féral L, Jeannin N, Castanet L. Testing analysis of prediction methods of Site Diversity at Ku and Ka-bands. In 25th AIAA International Communications Satellite Systems Conference, ICSSC. 2007; 7: 07-13.

[7] Rafiqul IM, Habaebi MH, Haidar IM, Lwas AK, Zyoud A, Singh M. Rain fade mitigation on earth-tosatellite microwave links using site diversity. In Communications (MICC), IEEE 12th Malaysia International Conference on. 2015: 186-191.

[8] Rafiqul IM, Muhammad N, Singh M, Lwas AK, Adawiyah R, Ismail A. Analysis of Rain Fade Mitigation Using Site Diversity on Earth-toSatellite Microwave links at Ku-Band. 5th Brunei International Conference on Engineering and Technology (BICET 2014), IET. 2014.

[9] Srivastava, N. Diversity Schemes for Wireless Communication-A Short Review. Journal of Theoretical and Applied Information Technology. 2010; 15(2): 134-143.

[10] Fišer O. Site diversity gain estimated from rain rate records. Radioengineering. $2003 ; 12(1): 9$.

[11] Timothy KI, Ong JT, Choo EB. Performance of the site diversity technique in Singapore: Preliminary results. IEEE communications letters. 2001; 5(2):49-51.

[12] Capsoni C, D'Amico M, Nebuloni R, Riva C. Performance of site diversity technique estimated from time diversity. InAntennas and Propagation (EUCAP). Proceedings of the 5th European Conference on,IEEE. 2011: 1463-1466.

[13] Pan QW, Allnutt JE, Tsui C. Evaluation of diversity and power control techniques for satellite communication systems in tropical and equatorial rain climates. IEEE Transactions on Antennas and Propagation. 2008; 56(10):3293-301.

[14] Kourogiorgas $\mathrm{Cl}$, Panagopoulos AD, Kanellopoulos JD. On the earth-space site diversity modeling: $\mathrm{A}$ novel physical-mathematical outage prediction model. IEEE Transactions on Antennas and Propagation. 2012; 60(9): 4391-7.

[15] Ippolito LJ, Ippolito Jr LJ. Satellite communications systems engineering: atmospheric effects, satellite link design and system performance. John Wiley \& Sons. 2017.

[16] Hodge D. An empirical relationship for path diversity gain. IEEE Transactions on Antennas and Propagation. 1976; 24(2):250-251.

[17] Recommendation ITU-R.618-12. Propagation data and prediction methods required for the design of Earth-space telecommunication systems. Geneva; 2015.

[18] Panagopoulos AD, Arapoglou PD, Kanellopoulos JD, Cottis PG. Long-term rain attenuation probability and site diversity gain prediction formulas. IEEE Transactions on Antennas and Propagation. 2005; 53(7):2307-13.

[19] Nagaraja C, Otung IE. Statistical prediction of site diversity gain on earth-space paths based on radar measurements in the UK. IEEE Transactions On Antennas And Propagation. 2012; 60(1):247-56.

[20] Semire FA, Mohd-Mokhtar R, Ismail W, Mohamad N, Mandeep JS. Modeling of rain attenuation and site diversity predictions for tropical regions. Annales Geophysicae (09927689). 2015 1; 33(3).

[21] Yeo JX, Lee YH, Ong JT. Performance of site diversity investigated through radar derived results. IEEE Transactions on Antennas and Propagation. 2011; 59(10):3890-8.

[22] Lwas AK, Islam MR, Habaebi MH, Mandeep SJ, Ismail AF, Daoud JI, Zyoud A. A modified effective path length for predicting rain attenuation based on measurements in Penang-Malaysia. ARPN Journal of Engineering and Applied Sciences. 2015; 10(21):10096-10100.

[23] Alhilali, Manhal, Jafri Din, Michael Schönhuber, and Hong Yin Lam. Estimation of Millimeter Wave Attenuation Due to Rain Using 2D Video Distrometer Data in Malaysia. Indonesian Journal of Electrical Engineering and Computer Science 7, no. 1 (2017): 164-169. 